\title{
Age-related differences in the US preexposure effect on conditioned taste aversion in rats
}

\author{
WILLIAM A. VALLIERE and JAMES R. MISANIN \\ Susquehanna University, Selinsgrove, Pennsylvania \\ and \\ CHARLES F. HINDERLITER \\ University of Pittsburgh at Johnstown, Johnstown, Pennsylvania
}

\begin{abstract}
Weanling, young adult, and old Wistar albino rats were used to determine whether the unconditioned stimulus (US) preexposure effect on conditioned taste aversion is age-related. The rats at each age level were given five preconditioning injections of either $.15 \mathrm{M}$ lithium chloride or physiological saline. These groups were then subdivided and given either conditioning or control treatments. Conditioning consisted of $10 \mathrm{~min}$ access to a saccharin solution followed $20 \mathrm{~min}$ later by an injection of $.15 M$ lithium chloride. The control treatment consisted of $10 \mathrm{~min}$ access to saccharin followed $20 \mathrm{~min}$ later by a saline injection. Twenty-four hours later the animals were given a 24-h two-bottle (saccharin vs. water) test. Results indicated that as age increased the US preexposure was less effective in attenuating conditioned taste aversion. These results were interpreted in terms of age differences in response to the conditioning context.
\end{abstract}

The association of a distinctive taste with illness occurs quite readily in rats. Usually a single pairing of a novel taste with illness is sufficient to obtain conditioned taste aversion (CTA). If, however, the rat has had preconditioning experience with either the illness (unconditioned stimulus [US] preexposure) or the taste (conditioned stimulus [CS] preexposure), the association may not occur or CTA may be greatly attenuated. Although there have been published reports of age differences in CTA (Baker, Baker, \& Kesner, 1977; Misanin, Blatt, \& Hinderliter, 1985) and in the CS preexposure effect (Misanin et al., 1985), there have not been, to our knowledge, any published reports of age differences in CTA due to US preexposure. CTA appears to be directly related to age in rats; that is, the older the rat, the more likely a taste-illness association will be formed. The CSpreexposure effect, on the other hand, is inversely related to age; that is, the older the animal, the less likely CS preexposure will attenuate CTA (Misanin et al., 1985). On the basis of these findings, it would be difficult to predict the direction age differences in the US-preexposure effect on CTA would take. If, on the one hand, aged animals are more likely to associate an illness with any stimulus, a strong context-illness association could be formed that might block a subsequent taste-illness association. On the other hand, if, as has been suggested for

This research was supported in part by Research Grant HD 21161 from the National Institute of Child Health and Human Development to the second author and in part by Research Grant BNS8418499 from the National Science Foundation to Douglas K. Candland. Reprint requests should be sent to James R. Misanin, Psychology Department, Susquehanna University, Selinsgrove, PA 17870. the CS-preexposure effect (Misanin et al., 1985), aged animals pay little attention to context, and if, as has been suggested (Batson \& Best, 1979), US-context associations are responsible for the US-preexposure effect, then US preexposure might have little, if any, effect on CTA in aged animals. Thus, the purpose of the present experiment was to determine whether there are age differences in the US-preexposure effect on CTA, and, if so, the direction these differences take.

\section{METHOD}

\section{Subjects}

Thirty-two weanling (21-24 days), 32 young adult (84-94 days), and 32 old (674-695 days) female Wistar albino rats were the subjects of this experiment. The animals were born and reared in the university animal colony. Animals of the same age and treatment were ear-notched for identification and were housed 4 to a cage in standard suspended galvanized rodent cages. They were maintained on an ad-lib feeding schedule at all times except during drinking sessions, which lasted $1 \mathrm{~h}$ or less.

\section{Apparatus}

All drinking sessions took place in drinking cages that were identical to the home cages except that they had three spring-grip clamps attached to the front of the cage to hold graduated (to $1 \mathrm{ml}$ ) 100 -ml cylinders equipped with rubber stoppers and stainless sipper tubes. One clamp was at the center and the other two were $35 \mathrm{~mm}$ in from each side of the front of the cage. During all drinking sessions except the test session, the cylinder was attached with the center clamp.

\section{Procedure}

The animals were deprived of water for $23 \mathrm{~h}$ and then given two daily 1-h adaptation sessions during which they had access to room-temperature tap water in the drinking cages. Preconditioning experience with the US (US-preexposure) was given to half of the animals at each age level. Preexposure consisted of five 1\%-body-weight intraperitoneal (i.p.) injections of .15 $\mathrm{M}$ lithium chloride $(\mathrm{LiCl})$. These injections were given 
$1.5 \mathrm{~h}$ before and $1.5 \mathrm{~h}$ after the first adaptation session, $1.5 \mathrm{~h}$ before and $1 \mathrm{~h}$ after the second adaptation session, and $1.5 \mathrm{~h}$ before conditioning. During these times nonpreexposed animals received $1 \%$-body-weight injections of $.9 \%$ sodium chloride $(\mathrm{NaCl})$. Half of the preexposed and half of the nonpreexposed animals at each age level underwent conditioning; the remaining halves received the control treatment. Conditioning consisted of $10 \mathrm{~min}$ access to a $.1 \%$ saccharin-sodium (w/v in tap water) solution followed $20 \mathrm{~min}$ later by a $1 \%$-body-weight i.p. injection of $.15 \mathrm{M} \mathrm{LiCl}$. The control treatment consisted of $10 \mathrm{~min}$ access to the saccharin solution followed 20 min later by a 1\%-body-weight i.p. injection of $.9 \% \mathrm{NaCl}$. Twenty-three hours after conditioning, all animals were given a two-bottle (saccharin vs. water) test. The side on which saccharin was presented was counterbalanced for all groups. The amount of saccharin and water ingested at each of four access times $(1,6,18$, and $24 \mathrm{~h}$ ) was recorded.

To summarize, the design of the experiment was a split-plot factorial design (SPF-223.4; Kirk, 1982) with preconditioning treatment (US preexposure vs. no preexposure), conditioning treatment (conditioning vs. control), and age (weanling, young adult, and old) as between subjects variables and their respective levels, and access time $(1,6,18$, and $24 \mathrm{~h}$ ) as the within-subject variable and its levels.

\section{RESULTS}

The amount of each solution drunk at each of the four access times was converted to a saccharin preference score: $100 \times \mathrm{ml}$ of saccharin $/(\mathrm{ml}$ of saccharin + water $)$. Group averages are depicted in Figure 1. A split-plot factorial analysis of variance was performed on these preference scores. With the significance level set at .05 , this analysis yielded significant main effects of age $[F(2,84)$ $=4.65]$ and significant preconditioning treatment $\times$ conditioning treatment $[F(1,84)=21.41]$ and age $\times$ preconditioning treatment $\times$ conditioning treatment $\times$ access time $[F(6,252)=4.02]$ interactions. Preference for saccharin was inversely related to age $\left[F_{\mathrm{s}}(1,84)>5.29\right]$, and preexposed subjects given $\mathrm{LiCl}$ during the conditioning treatment showed a significantly greater preference for saccharin than did nonpreexposed subjects given $\mathrm{LiCl}$ during conditioning $[F(1,84)=64.34]$. The preexposed and nonpreexposed subjects given saline during the con-

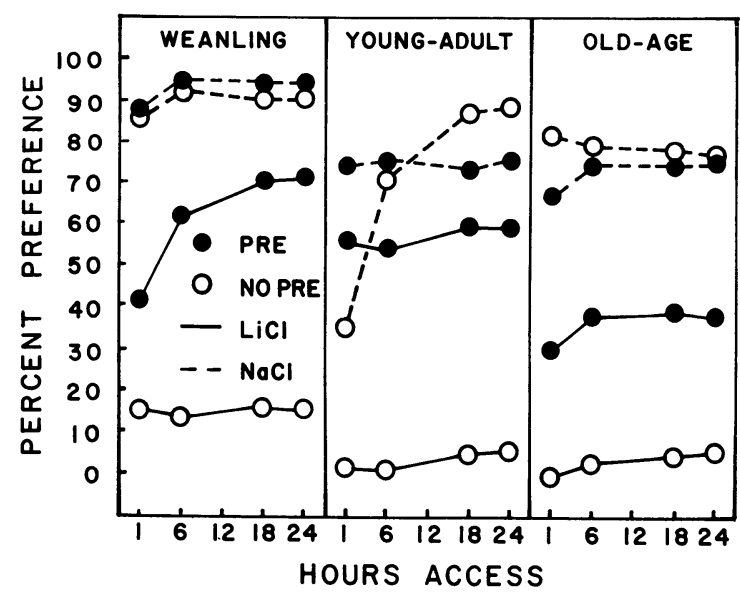

Figure 1. Mean percent preference for saccharin as a function of age, preconditioning treatment (US preexposure vs. no US preexposure), and conditioning treatment ( $\mathrm{LiCl}$ vs. $\mathrm{NaCl})$. ditioning treatment, on the other hand, failed to differ $[F(1,84)<0.01]$. Between-age comparisons within treatment groups showed that the nonpreexposed animals given $\mathrm{LiCl}$ during conditioning did not differ significantly from each other $\left[F_{\mathrm{S}}(1,84)<1.16\right]$, whereas the preexposed weanlings differed significantly from the preexposed old rats $[F(1,84)=4.47]$. The saccharin preference of the preexposed young adults occupied an intermediate position that failed to differ from the saccharin preferences of both the weanlings $[F(1,84)=0.90]$ and the old rats $[F(1,84)=3.17](p s=.08)$. The four-factor interaction was the result of the nonpreexposed young adult saline-control rats showing an initial aversion to saccharin during testing and a subsequent steady increase in preference for the saccharin solution.

\section{DISCUSSION}

The present results indicate that the older the rat, the less likely preconditioning experience with the US is to interfere with conditioning an aversion to a novel taste. The present findings are identical to those we found with CS preexposure (Misanin et al., 1985). In both cases, that is, with both CS and US preexposure, younger animals showed a greater attenuation of CTA than did older animals. It seems clear that, at least following US preexposure, this stronger taste-illness association in the older rats is not due to age differences in the efficacy of $\mathrm{LiCl}$ or to the older animals' receiving a greater absolute dosage of the illness-inducing agent. The US preexposure effect is directly related to US intensity (Cannon, Berman, Baker, \& Atkinson, 1975). Thus, if older animals were experiencing a more intense US as a result of a larger weight-related injection or an aging-related debilitation, then we should expect a greater attentuation of taste aversion learning in the older animals. We believe, rather, that these results, as well as others, can be explained on the basis of age-related changes in attention to context.

There are a number of experimental procedures that, like US preexposure, tend to weaken CTA in rats and bring out age differences in CTA that might otherwise be obscured. As already mentioned, preexposure to the CS weakens CTA and accentuates age differences in taste aversion learning (Misanin et al., 1985). Lengthening the interstimulus (i.e., CS-US) or trace interval is another experimental manipulation that weakens CTA (Kalat \& Rozin, 1973) and leads to apparent age differences in the formation of taste-illness associations (Martin \& Timmins, 1980; Steinert, Infurna, Jardula, \& Spear, 1979). Reducing the intensity of the CS (Martin \& Timmins, 1980) or the intensity of the US (Martin \& Timmins, 1980; Misanin et al., 1985) also leads to age differences in CTA. Further support for the latter finding can also be gleaned from the present results. Using a relatively intense US, we found no age differences in CTA in the absence of US preexposure.

Age differences in CTA brought about by experimental procedures that weaken conditioning can be explained on the basis of age differences in attention to contextual cues. Poorer conditioning over long trace intervals, for example, may be attributed to greater conditioning to contextual cues (Marlin, 1981). Thus, if young animals attend to contextual cues more than do older animals, they should show greater conditioning to context, and hence less CTA, than do older animals (e.g., Steinert et al., 1979).

Age differences in CTA as a result of reduction in CS and US intensity can also be explained on the basis of age differences in attention to context. Siegel, Richardson, and Campbell (1986) recently reported that the rat's reaction to a novel stimulus in a familiar environment is greater than its reaction to the same stimulus in a novel or unfamiliar environment. This is what might be expected if the rat focuses its attention on the novel stimulus rather than on other aspects of the environment. The rat would be more likely to focus its attention on a novel stimulus in an environment to which it need not attend, that is, a familiar environment, than in an unfamiliar environment to which it needs to attend. In effect, inattention to context leads to a subjective increase 
in the intensity of the novel stimulus (see also Mitchell, Winter, \& Moffitt, 1980). Thus, if older animals are less attentive to context than are younger animals, they should experience the most subjectively intense US or CS and, consequently, the greatest degree of conditioning. Such age differences in CTA would be obscured if the physical intensity of the CS or US were great enough to require focal attention at all age levels; Misanin et al. (1985) showed that age differences in taste aversion conditioned in a differentially familiar environment do disappear when US intensity is increased.

Age differences in CTA as a result of preconditioning experience with the CS have been explained by age differences in attention to context (Misanin et al., 1985). Age differences in CTA as a result of US preexposure can be explained in a similar manner. Wagner (1978) proposed that the formation of a CS-US association depends on active representation of the stimuli in short-term memory. If the presentation of the US at the time of conditioning is responsible for its active representation, then an association will be formed. On the other hand, if the US has been prerepresented in short-term memory at the time of conditioning as a result of the retrieval action of cues with which it previously had been associated, then a CS-US association is less likely to be formed. During US preexposure, then, the animal may form an association with the context in which the stimulus occurs. Thus, during conditioning in the same context, the contextual cues prime a representation of the USto-be in short-term memory and, consequently, the CS and US are less likely to become associated (Wagner, 1978). If, as we have assumed, the ease with which the rat associates either the CS or US with the context is age related, then age differences in CTA as a result of CS or US preexposure conform to Wagner's (1978) information processing model. Misanin et al. (1985) suggested that it is reasonable to assume that there are age differences in attention to the conditioning context used in the present study. Old rats may have attended less to the conditioning context than did weanling and young adult rats because they had been living in similar cages for many months. Consequently, little association between context and US would occur to block a taste-illness association. Weanling rats, on the other hand, which previously had been living in a nesting context that was quite different form the conditioning context, may have given more attention to the novel conditioning environment and, consequently, formed an association between the context and the US. This association may have then blocked, through a priming action, the taste-illness association.

Age differences in attention to context can explain the present results in yet another way. Data collected by Pumo and Spear (1986) suggest a novel interpretation of the US-preexposure effect. Their data suggest that if a CS is paired with an aversive US in an aversive context, the conditioning that results, as assessed by a retention test, is weaker than the conditioning brought about by the same CS and US paired in a nonaversive context. Thus, if aged animals are less attentive to context than are younger animals, the context in which the old rats in the present experiment experienced $\mathrm{LiCl}$ preexposure should have been less aversive for them than for the younger rats, due to a weaker context-illness association; hence, the taste- $\mathrm{LiCl}$ pairing experienced in the same context should have led to greater taste aversion for them than for the younger animals. Context, then, as a result of being paired with the US, may interfere with conditioning not through blocking per se, but through a change in its affective value.

Alternatively, since the last US preexposure occurred shortly before the conditioning trial, the US-preexposure effect observed in the present study may depend not on a context-illness association or context-related priming, but, rather, on self-generated priming (Wagner, 1978). If this is the case, the present results would suggest that old animals are less likely to maintain an active representation of the US in short-term memory over the US-US (i.e., preexposure-conditioning) interval.

\section{REFERENCES}

BAKer, L. J., BAKER, T. B., \& Kesner, R. P. (1977). Taste aversion learning in young and adult rats. Journal of Comparative \& Physiological Psychology, 91, 1168-1178.

BATSON, J. D., \& BEST, P. J. (1979). Drug-preexposure effects in flavoraversion learning: Associative interference by conditioned environmental stimuli. Journal of Experimental Psychology: Animal Behavior Processes, 5, 272-283.

Cannon, D. S., Berman, R. F., Baker, T. B., \& Atkinson, C. A. (1975). Effect of preconditioning unconditioned stimulus experience on learned taste aversions. Joumal of Experimental Psychology: Animal Behavior Processes, 104, 270-284.

KalaT, J. W., \& Rozin, P. (1973). "Learned safety” as a mechanism in long-delay taste-aversion learning in rats. Journal of Comparative \& Physiological Psychology, 83, 198-207.

KIRK, R. E. (1982). Experimental design: Procedures for the behavioral sciences. Belmont, CA: Brooks/Cole.

Marlin, N. A. (1981). Contextual associations in trace conditioning. Animal Learning \& Behavior, 9, 519-523.

Martin, G. N., \& Timmins, W. K. (1980). Taste-sickness associations in young rats over varying delays, stimulus, and test conditions. Animal Learning \& Behavior, 8, 529-533.

Misanin, J. R., Blatt, L. A., \& Hinderliter, C. F. (1985). Age dependency in neophobia: Its influence on taste-aversion learning and the flavor preexposure effect in rats. Animal Learning \& Behavior, 13, 69-76.

Mitchell, D., Winter, W., \& Moffitt, T. (1980). Cross-modality contrast: Exteroceptive context habituation enhances taste neophobia and conditioned taste aversions. Animal Learning \& Behavior, 8, 524-528.

Pumo, J., \& SPEAR, N. E. (1986, November). The affective value of the context determines retention of Pavlovian conditioning in the 7day old rat. Paper presented at the meeting of the International Society for Developmental Psychobiology, Annapolis, MD.

Siegel, M. A., Richardson, R., \& CAMpbell, B. A. (1986, November). Sensory information processing during adaptation to an unfamiliar environment in the developing rat . Paper presented at the meeting of the International Society for Developmental Psychobiology, Annapolis, MD.

Steinert, P. A., Infurna, R. N., Jardula, M. F., \& Spear, N. E. (1979). Effects of CS concentration on long-delay taste aversion learning in preweanling and adult rats. Behavioral \& Neural Biology, 27, 487-502.

WAGNER, A. R. (1978). Expectancies and the priming of STM. In S. H. Hulse, H. Fowler, \& W. K. Honig (Eds.), Cognitive processes in animal behavior. New York: Wiley.

(Manuscript received for publication June 19, 1987.) 